УДК $547.3+615.3$

\title{
СИНТЕЗ ПРОИЗВОДНЫХ ГОССИПОЛА С ГЕТЕРОЦИКЛИЧЕСКИМИ
} АМИНАМИ

\section{() A.X. Хаитбаев}

\author{
Национальный университет Узбекистана им. М. Улугбека, Вузгородок, \\ Ташкент, 100174 (Республика Узбекистан), e-mail: polyphenol-10@yandex.ru
}

Взаимодействием госсипола с аминосоединениями гетероциклической природы в среде этанола синтезирован ряд новых оснований Шиффа. С помощью методов УФ-, ИК- и ПМР-спектроскопии изучены индивидуальность и чистота синтезированных соединений.

Ключевые слова: госсипол, основания Шиффа, азометиновые производные, on-line режим.

\section{Введение}

Из давних времен различные биологически активные вещества, получаемые из растений, широко используются в народной медицине, фармацевтике, пищевой промышленности и в различных отраслях народного хозяйства. К таким техническим растениям также относится хлопчатник. В составе коры, стеблей и семени хлопчатника встречается госсипол. Госсипол за счет двух карбонильных групп в молекуле очень легко взаимодействует с различными аминосоединениями (в соотношении $1: 2$ ), образуя основания Шиффа. Среди таких производных госсипола ранее были синтезированы вещества, проявляющие различные биологические свойства [1-3]. В связи с этим цель настоящей работы - синтез ряда производных госсипола с гетероциклическими аминами, такими как аденин, 2-аминотиазол, 2-амино-4-метил-5-бром-6гидроксопиримидин и др.

\section{Экспериментальная часть}

Синтез новых азометиновых производных госсипола осуществляли по следующей схеме [4]:<smiles>[R]NC=C1C(=O)C(O)=C(C(C)C)c2cc(C)c(C)c(O)c21</smiles>

Ход протекания реакции проверяли с помощью ТСХ. Определили некоторые физико-химические константы синтезированных соединений. При этом все вещества имели цвет от желтого до красного. Некоторые физико-химические свойства полученных соединений приведены в таблице.

Строение и индивидуальность всех синтезированных соединений были изучены с помощью УФ-, ИК- и ПМР-спектроскопии. УФ-спектр изучали с помощью СФ-26 спектрофотометра, ИК-спектр снимали

Хаитбаев Алимер Хамидович - заведующий межвузовской лабораторией «Физико-химические методы исследования», кандидат химических наук, е-mail: polyphenol-10@yandex.ru с помощью прибора UR-20 (толщина кюветы 10 мм, в виде таблеток с $\mathrm{KBr}$ ) и ПМР-спект снимали с помощью UNITY-400 (фирмы Varian, 400 МГц, растворитель ДМСO-D 6 ). 
Некоторые физико-химические свойства полученных соединений

\begin{tabular}{|c|c|c|c|c|c|c|c|}
\hline \multirow{2}{*}{ Вещество } & \multirow{2}{*}{ Радикал - R } & \multirow{2}{*}{$\mathrm{T}_{\text {пл., }}{ }^{\circ} \mathrm{C}$} & \multicolumn{3}{|c|}{$R_{f}$} & \multirow{2}{*}{ Выход, \% } & \multirow{2}{*}{ Цвет } \\
\hline & & & 1 & 2 & 3 & & \\
\hline I & & $261-263$ & 0,51 & 0,52 & 0,63 & 36,5 & $\begin{array}{c}\text { Темно- } \\
\text { желтый }\end{array}$ \\
\hline II & & $254-256$ & 0,54 & 0,62 & 0,63 & 72,2 & Желтый \\
\hline III & & $215-217$ & 0,57 & 0,7 & 0,76 & 77,5 & Красный \\
\hline IV & & $205-207$ & 0,50 & 0,67 & 0,57 & 73,78 & Желтый \\
\hline V & & $285-287$ & 0,49 & 0,51 & 0,55 & 82,3 & $\begin{array}{c}\text { Темно } \\
\text { желтый }\end{array}$ \\
\hline VI & & $228-229$ & 0,51 & 0,74 & 0,69 & 72,4 & Оранжевый \\
\hline VII & & $277-278$ & 0,31 & 0,70 & 0,77 & 39 & Желтый \\
\hline VIII & & 200-201 & 0,78 & 0,55 & 0,37 & 71 & Оранжевый \\
\hline IX & & $250-251$ & 0,35 & 0,62 & 0,75 & 73,3 & Желтый \\
\hline
\end{tabular}

Системы: ${ }^{1}$ Гексан - ацетон $(3: 2,5) ;{ }^{2}$ Бензол - ацетон $(5: 1,5) ;{ }^{3}$ Бензол - этанол $(3: 1)$

\section{Обсуждение результатов}

Из литературных данных известно, что пуриновые и пиримидиновые азотные основания проявляют основность [5]. Для изучения влияния основности веществ на выход реакции, биологическую активность, кинетику реакции, таутомерную состояния веществ и других свойств, нашей следующей задачей стало определение основности как первоначальных, так и синтезированных производных госсипола. Для этой цели провели потенционометрическое титрование с помощью рН-метр-милливольтметра рН-673М.

По полученным данным были определены следующие значения основности: 2-аминотиазол - 9,0, аденин - 8,0, производный госсипола с 2-аминотиазолом - 8,5, для производного госсипола с аденином 7,6 соответственно.

В УФ-спектре аденина максимумы поглощения проявляются в области 208,24 и 260,89 нм. А для самого госсипола эти максимумы проявляются в области 236,26, 289,88 и 374,00 нм.

Максимумы поглощения в УФ-спектроскопии для синтезированного производного госсипола с аденином проявлялся в области 207,79, 248,5 и 383,2 нм.

В ИК-спектре аденина имеются следующие сигналы оответствующие различным колебаниям: при 3355-3294 см с $^{-1}$ валентные колебания $\mathrm{NH}_{2}$-группы, при 1449-1602 см-1 валентные колебания $-\mathrm{C}=\mathrm{C}-\mathrm{cвязи,}$ 
при 1250-1306 см-1 валентные колебания $-\mathrm{N}=\mathrm{C}-$ связи и др. А для самого госсипола имеются следующие сигналы при $1578 \mathrm{~cm}^{-1} v_{\mathrm{C}=\mathrm{C}}$, при $1710 \mathrm{~cm}^{-1}$ валентные колебания СНО-группы; при 2874-2929 см-1 асимметрические и симметрические валентные колебания $\mathrm{CH}_{3}$-группы; при $1440 \mathrm{~cm}^{-1}$ асимметрические деформационные колебания $\mathrm{CH}_{3}$-группы;при 1360-1380 см-1 симметрические деформационные колебания $\mathrm{CH}_{3}$-группы; при 3513-3422 см-1 валентные колебания внутри- и межмолекулярных Н-связей.

При изучение ИК-спектра синтезированного производного госсипола с аденином основную информацию о протекании реакции дает сигналы, соответствующие для СНО-группы. Так как при реакции сигналы при $1711 \mathrm{~cm}^{-1}$ (соответствующие для СНО-группы) исчезают, а вместо них появлются сигналы

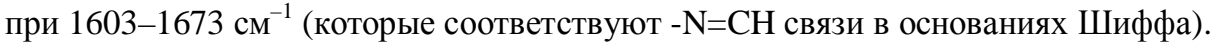

В ПМР-спектре аденина получены следющие значения: при 2,46 м.д. дублет (для $\left.\mathrm{C}_{8}-\mathrm{H}\right)$, при 3,2 м.д. синглет (для $\mathrm{C}_{2}-\mathrm{H}$ ), при 6,9 м.д. синглет (для $\mathrm{NH}_{2}$-), при 7,9-8,2 м.д. дублет (для $\mathrm{NH}-$ ). А в ПМР-спектре для самого госсипола получены следующие значения: при 1,4-1,4 м.д. мултиплет (для $6 \mathrm{H}=2 \times \mathrm{CH}_{3}$ в изопропилной группе), при 1,9-2,0 м.д. синглет (для 3Н= $\mathrm{CH}_{3}$ ), при 3,1 м.д. (для -СН), при 7,1-7,2 м.д. мултиплет (для $\left.\mathrm{C}_{4}-\mathrm{H}\right)$, при 9,0-10,1 м.д. (для ОН), при 11,2-11,7 м.д. (для -СНО).

Образование продукта реакции (например, производное госсипола с аденином) определяли по тому, как изчезанию сигналов при 11,2-11,7 м.д. (соответствующие -СНО группе) и появлению сигналов при 8,2-8,2 м.д. (принадлежащие -NH-CH группе). Также для этого соединения имелись следующие сигналы: при 1,47-1,40 м.д. мультиплет (для $6 \mathrm{H}=2 \times \mathrm{CH}_{3}$ в изопропильной группе), при 2,03 м.д. синглет (для $3 \mathrm{H}=\mathrm{CH}_{3}$ ), при 7,14-7,18 м.д. мультиплет (для $\mathrm{C}_{4}-\mathrm{H}$ ), 9,97-10,77 м.д. (для $\mathrm{H}=\mathrm{OH}$ ).

Также с помощью УФ-, ИК- и ПМР-спектроскопии были изучены строения и других синтезированных оснований Шиффа госсипола с другими гетерциклическими аминосоединениями. Все полученные данные подтверждают индивидуальность и строение полученных веществ.

$\mathrm{B}$ on-line режиме с помощью специальной компьютерной программы самостоятельно провели вычисления физико-химических и других параметров для выявления некоторой биологической активностий синтезированных нами соединений [6]. По полученным данным установлено, что высокую активность против вируса герпеса и туберкулеза проявляет производное госсипола с аденином, против различных бактерий - с 2-амино-4,6-диметилпиримидином, против раковых опухолей - с гуанином, антиоксидантная активность с 2-аминопиримидином, иммунномодулирующая активность с 2-амино-4,6-диметил пиримидином, интерферон-индуцирующая активность с 2-амино-4-метил-5-бром-6-гидроокспиримидином и т.д. Также было вычислено, что некоторые синтезированные соединения вообе не проявляют биологическую активность против определенных болезней, в частности, производное госсипола с 2-аминотиазолом и 3-амино-5-метил пиразолом не проявляет иммунномодулирующую активность, а с гуанином не проявляет активность против тубуркулеза и т.д.

\section{Заключение}

Таким образом, при взаимодействии госсипола с аминосоединениями гетероциклической природы в среде этанола синтезирован ряд новых оснований Шиффа. С помощью методов УФ-, ИК- и ПМРспектроскопии исследованы спектральные характеристики синтезированных соединений и установлена их чистота.

\section{Список литературы}

1. Ауелбеков С.А., Мирзаабдуллаев А.Б. Синтез и противовирусная активность производных госсипола // Химико-фармацевтический журнал. 1985. №7. С. 829-831.

2. Барам Н.И., Исмаилов А.И. Биологическая активность госсипола и его производных // Химия природных соединений. 1993. №3. С. 334-348.

3. Хаитбаев А.Х., Тилябаев 3., Ачилова Г.Ш,, Хаитбаев Х.Х., Ауелбеков С.А. Синтез и биологическая активность некоторых производных госсипола // Химия природных соединений. 1995. №1. С. 56-58.

4. Хаитбаев А.Х., Асланов Х.А., Ауелбеков С.А., Хаитбаев Х.Х., Сайиткулов А.М. Синтез новых иминопроизводных госсипола // Химия природных соединений. 1994. №1. С. 48-49.

5. Verdolino V., Cammi R., Munk B.H., Schlegel H.B. Calculation of $\mathrm{pKa}$ Values of Nucleobases and the Guanine Oxidation Products Guanidinohydantoin and Spiroiminodihydantoin using Density Functional Theory and a Polarizable Continuum Model // J. Phys. Chem. B. 2008. Vol. 112. Pp. 16860-16873.

6. Поройков В.В. Компьютерное предсказание биологической активности веществ: пределы возможного // Химия в России. 1999. №2. С. 8-12. 


\section{Khaitbaev A.Kh. SYNTHESIS OF GOSSYPOL DERIVATIVES WITH HETEROCYCLIC AMINES}

National University of Uzbekistan named after M. Ulugbek, Tashkent, 100174, (Uzbekistan), e-mail:polyphenol-10@yandex.ru

Interaction of gossypol with amino compounds heterocyclic nature in ethanol synthesized a series of new Schiff bases. Using the methods of UV, IR and NMR spectroscopy study individuality and purity of the synthesized compounds.

Keywords: gossypol, Schiff bases, azomethin derivatives, on-line mode.

\section{References}

1. Auelbekov S.A., Mirzaabdullaev A.B. Khimiko-farmatsevticheskii zhurnal, 1985, no. 7, pp. 829-831. (in Russ.).

2. Baram N.I., Ismailov A.I. Khimiia prirodnykh soedinenii, 1993, no. 3, pp. 334-348. (in Russ.).

3. Khaitbaev A.Kh., Tiliabaev Z., Achilova G.Sh,, Khaitbaev Kh.Kh., Auelbekov S.A. Khimiia prirodnykh soedinenii, 1995, no. 1, pp. 56-58. (in Russ.).

4. Khaitbaev A.Kh., Aslanov Kh.A., Auelbekov S.A., Khaitbaev Kh.Kh., Saiitkulov A.M. Khimiia prirodnykh soedinenii, 1994, no. 1, pp. 48-49. (in Russ.).

5. Verdolino V., Cammi R., Munk B.H., Schlegel H.B. J. Phys. Chem. B., 2008, vol. 112, pp. 16860-16873.

6. Poroikov V.V. Khimiia v Rossii, 1999, no. 2, pp. 8-12. (in Russ.). 